\title{
Memory Complaints Are Frequent but Qualitatively Different in Young and Elderly Healthy People
}

\author{
Sandra Ginó ${ }^{a, f}$ Tiago Mendes ${ }^{a, d}$ João Maroco ${ }^{e}$ Filipa Ribeiro $^{a, e}$ \\ Ben A. Schmand ${ }^{g} \quad$ Alexandre de Mendonça $^{a, c}$ Manuela Guerreiro ${ }^{a, b}$ \\ ${ }^{a}$ Dementia Clinics, ${ }^{b}$ Laboratory of Language, and ${ }^{C}$ Laboratory of Neurosciences, Institute of Molecular \\ Medicine and Faculty of Medicine, University of Lisbon, dDepartment of Psychiatry, Santa Maria Hospital, \\ eSuperior Institute of Applied Psychology, and fSanta Casa da Misericórdia de Lisboa, Lisbon, Portugal; \\ gFaculty of Social and Behavioural Sciences, University of Amsterdam, Amsterdam, The Netherlands
}

\section{Key Words}

Memory complaints - Subjective Memory Complaints scale •

Memory impairment $\cdot$ Depression

\section{Abstract}

Background: Subjective memory complaints are frequently reported by the elderly. There is less information about the characterization of subjective memory complaints in young people. Objective: To determine different memory complaints between young and elderly people with the use of the Subjective Memory Complaints (SMC) scale. Methods: Participants were volunteers attending a health itinerant unit, a blood donor centre, a leisure centre for retired people, a senior citizens college or university. All participants were questioned about their own memory abilities using the SMC scale and assessed for the presence of depressive symptoms. Results: Nine-hundred and forty-six subjects aged 18-92 years were included in the study. The mean total score on the SMC scale was $4.89 \pm 3.03$, and $75.9 \%$ of the participants had at least minor complaints about their memory. Older people had more general memory complaints and reported they were more likely to become transiently confused, whereas younger people reported they were more frequently told by others that they were forgetful and would more often take notes. Conclusions: Memory complaints were frequent both in young and elderly subjects, but the detailed assessment revealed age-related differences in the type of complaints.

Copyright $\odot 2009$ S. Karger AG, Basel

\section{Introduction}

Subjective memory complaints are frequently reported by older people [1-3]. Many studies have focused on the subjective memory complaints of the elderly, since these correlate with subsequent global cerebral metabolic decline [4], and possibly predict the progression to objective memory impairment and dementia $[5,6]$. In contrast, the characterization of subjective memory complaints in younger people has been largely neglected. Available evidence suggests that subjective memory complaints are frequent in young people. In a large community-based study, in which approximately 2,000 adult participants were asked to answer the question 'Do you consider yourself as being forgetful?', as much as $29.4 \%$ of young adults (25-35 years old) and 33.9\% of middle-aged adults (40-50 years old) considered themselves forgetful

\section{KARGER \\ Fax +4161306 1234 \\ E-Mail karger@karger.ch}

www.karger.com
(C) 2009 S. Karger AG, Basel

0304-324X/10/0563-0272\$26.00/0

Accessible online at:

www.karger.com/ger
Alexandre de Mendonça

Laboratory of Neurosciences, Institute of Molecular Medicine

Av. Prof. Egas Moniz

PT-1649-028 Lisbon (Portugal)

Tel. +351 217985 183, Fax +351 217999 454, E-Mail mendonca@fm.ul.pt 
[7]. In another community-based study enrolling 810 participants, with a high frequency of psychiatric diagnoses, $14.5 \%$ of the subgroup of young (18-44 years old) subjects reported memory complaints when answering the question 'Do you find that you have trouble with your memory?' [8].

Different instruments have been used to assess subjective memory impairment $[6,9]$. In a previous study, we applied a formal scale, the Subjective Memory Complaints scale (SMC) [10], instead of a single question, to characterize subjective memory complaints in 292 adult healthy participants. Interestingly, no association was found between the total SMC score and age [11]. However, the possibility remains that young and old people may report qualitatively different subjective memory complaints. In the present study, we planned to gather a larger sample, powered to test whether young and elderly people might score differently on the subtypes of memory complaints reflected in the distinct items of the SMC scale. Education, gender, and the presence of depressive symptoms were entered as covariates in the analysis because they are known determinants of subjective memory complaints [11]. Since young individuals tend to ascribe their complaints to extrinsic causes like emotional problems and stressful life events [7], they might score higher on items that refer to attention and concentration. The finding of different profiles of subjective memory complaints in the young and elderly would contribute to the understanding of memory changes across the life span. These profiles would also detect changes from the normal pattern either in young or elderly subjects.

\section{Methods}

\section{Recruitment}

Participants were volunteers attending a health itinerant unit that aims to screen and promote general health, a blood donor centre, a leisure centre for retired people, a senior citizens college or university, all in the area of Lisbon.

The inclusion criterion was: subjects in community dwellings willing to participate in the present study.

The exclusion criteria were: (1) Mini-Mental State Examination (MMSE) score below cutoff (for participants $>40$ years old); (2) history of depression or medication with antidepressive drugs; (3) neurological or psychiatric conditions or systemic diseases able to interfere with cognition; (4) psychoactive medications with possible influence on cognition; (5) chronic alcohol or drug abuse; (6) sensory deficits likely to interfere with assessment; (7) non-native Portuguese speakers.

Before any procedure, all participants gave their informed consent. The present study was approved by the local ethics committee.

\section{Procedures}

A semi-structured interview recorded clinical information, present and past medical conditions, psychiatric and neurological history, medication, and social and familial status. The MMSE $[12,13]$ screened cognitive decline in participants $>40$ years old, subjects with MMSE below education-adjusted values for the Portuguese population were excluded $(<16,<23$ and $<28$ for illiterate, $1-11$ and $>11$ years of education, respectively; see, for instance, Uhlmann and Larson [14] for the effect of education on MMSE cutoff scores).

\section{Assessment of Subjective Memory Complaints}

All participants were assessed with the SMC scale $[10,15]$. They were required to answer 10 individual items concerning difficulties in daily life memory tasks, with total scores ranging from 0 (absence of complaints) to 21 (maximal complaints score). These items are considered representative of common memory complaints [10].

\section{Assessment of Depression}

For the assessment of depressive symptoms, three scales were used in different subsets of participants. The Geriatric Depression Scale $[16,17]$ and the depression scale from the Consortium to Establish a Registry for Alzheimer's Disease (CERAD) [18] were used in subjects $>40$ years, and the Beck Depression Inventory (BDI) $[19,20]$ was applied in subjects $\leq 40$ years. Subjects were classified as having significant depressive symptoms if they scored $>4$ on the GDS [21], $>4$ on the CERAD depression scale [22], or $>15$ on the BDI [20].

\section{Statistical Analysis}

Pearson and point-biserial correlation coefficients between the total SMC score and covariates were obtained. The effects of the age group on the total SMC score were evaluated by an ANCOVA using education, gender and the presence of depressive symptoms as covariates, after checking assumptions, namely homogeneity of variances and regression slopes. Since individual items of the SMC scale are ordinal in nature, and to warrant protection against the inflation of type I statistical error resulting from multiple item comparisons, a nonparametric MANCOVA was performed on the ranks of the Likert-type SMC items, using education, gender and the presence of depressive symptoms as covariates (for details on this nonparametric statistical procedure see references $[23,24])$. The statistically significant nonparametric MANCOVA was then followed by the nonparametric KruskalWallis ANOVA on ranks to identify which SMC items were affected by the age classes. Finally, a multiple mean rank comparisons analysis was performed to identify which age classes differed significantly for the SMC items. Since there were 7 age classes, the robustness and protection against type I error inflation due to multiple comparisons of the procedure [23] was checked with the nonparametric MANCOVA [25].

Statistical significance was accepted at $\mathrm{p}<0.05$. Data were analyzed using SPSS 15.0 for Windows (SPSS, Inc., Chicago, Ill., USA) and our own designed SPSS scripts implementing the nonparametric MANCOVA procedures [23, 25]. 


\section{Results}

Nine-hundred and forty-six subjects, aged 18-92 years, were included in the study. Demographic characteristics and the presence of depressive symptoms are shown in table 1.

Subjective memory complaints were frequent. The mean total score of the SMC was $4.89 \pm 3.03$, and $75.9 \%$ of the participants had at least minor complaints about their own memory (item 1 of the SMC scale; table 2). Using this scale, we found that the most frequently reported difficulties were to forget where things are left $(60.9 \%$, item 4 ) and the need to take notes so as to avoid forgetting things ( $56.7 \%$, item 5 ; table 2 ).

Specific aspects of subjective memory complaints measured by different SMC scale items were rated differently in young and elderly subjects. Since the total SMC score was correlated with education $(r=0.116)$, gender $(\mathrm{r}=0.124)$ and the presence of depressive symptoms $(r=0.271)$, the nonparametric MANCOVA analysis performed on the ranks of the SMC items used education, gender and the presence of depressive symptoms as covariates, revealing a statistically significant effect of the age groups on the $10 \mathrm{SMC}$ items $\left[\chi^{2}(60)=156.82\right.$; $\mathrm{p}<$ $0.001]$. Analysis of ranks of individual items showed that older people had more general memory complaints (item $1 ; \mathrm{p}<0.001)$ and reported they were more likely to become transiently confused (item $9 ; \mathrm{p}=0.003$ ), whereas younger people reported they were more frequently told by others that they were forgetful (item $2 ; \mathrm{p}<0.001$ ) and would more often take notes (item $5 ; \mathrm{p}=0.036$ ). The other items of the SMC scale were not significantly affected by age (fig. 1).

\section{Discussion}

The present study shows that, although memory complaints are common across the life span, young and elderly subjects complain about their memory differently.

The presence of at least subtle memory complaints was very frequent, with $75.9 \%$ of participants reporting some complaints about their memory (item 1 of SMC scale: Do you have any complaints concerning your memory?). When compared to a previously reported study with Dutch subjects aged 65 years or older using the same questionnaire [10], our study shows a greater prevalence of complaints concerning one's memory (39.8\%; item 1 of the SMC scale). Using a similar item 'Do you consider yourself as being forgetful?', Ponds et al. [7] found that
Table 1. Demographic characteristics and the presence of significant depressive symptoms

\begin{tabular}{ll}
\hline Participants & 946 \\
Age, years & $54.2 \pm 20.1$ \\
Mean \pm SD & $18-92$ \\
Range & \\
Age group & 191 \\
$18-29$ & 59 \\
$30-39$ & 95 \\
$40-49$ & 136 \\
$50-59$ & 198 \\
$60-69$ & 205 \\
$70-79$ & 62 \\
$\geq 80$ & $569(60.1 \%)$ \\
Sex & $377(39.9 \%)$ \\
Female & \\
Male & $8.2 \pm 4.9$ \\
Education, years & $0-19$ \\
Mean \pm SD & \\
Range & 44 \\
Education category & 365 \\
0 years & 236 \\
1-4 years & 301 \\
5-11 years & $228(24.1 \%)$ \\
$\geq 12$ years & \\
Depressive symptoms & \\
\hline
\end{tabular}

$38.8 \%$ of Dutch adults reported memory difficulties. The higher values for the frequency of memory complaints found in the present study could be accounted for by cultural differences between Dutch and Portuguese populations. However, no major differences were found in personality factors when comparing the Portuguese population with other cultures [26]. This could also have resulted from a social acquiescence bias because participants were somehow worried about their memory.

Our findings confirmed that older subjects present, in general, more memory complaints than younger ones, as evidenced by a higher score on item 1 of the SMC scale. A slight increase in the prevalence of memory complaints with age was also reported using a single question about forgetfulness [7]. The previous observation from our group that, after adjusting for the effects of gender, education and the presence of depressive symptoms, the total SMC score was not significantly different between younger and older participants [11] might in fact suggest that younger and older people could score differently on distinct items of the SMC scale, cancelling a net effect on the total score. Furthermore, it is known that young and elderly subjects give different reasons to explain their own memory difficulties. Young individuals may attribute 
Fig. 1. Evolution with age (decades) of the scores on individual SMC items (as mean ranks). Regression lines are drawn. The scores on items 1 (Do you have complaints concerning your memory?) and 9 (Do your thoughts ever become confused?) significantly increased with age. In contrast, the scores on items 2 (Do other people find you forgetful?) and 5 (Do you often use notes to avoid forgetting things?) significantly decreased with age. QSM = Portuguese version of Subjective Memory Complaint Scale.



Table 2. Results of the SMC scale

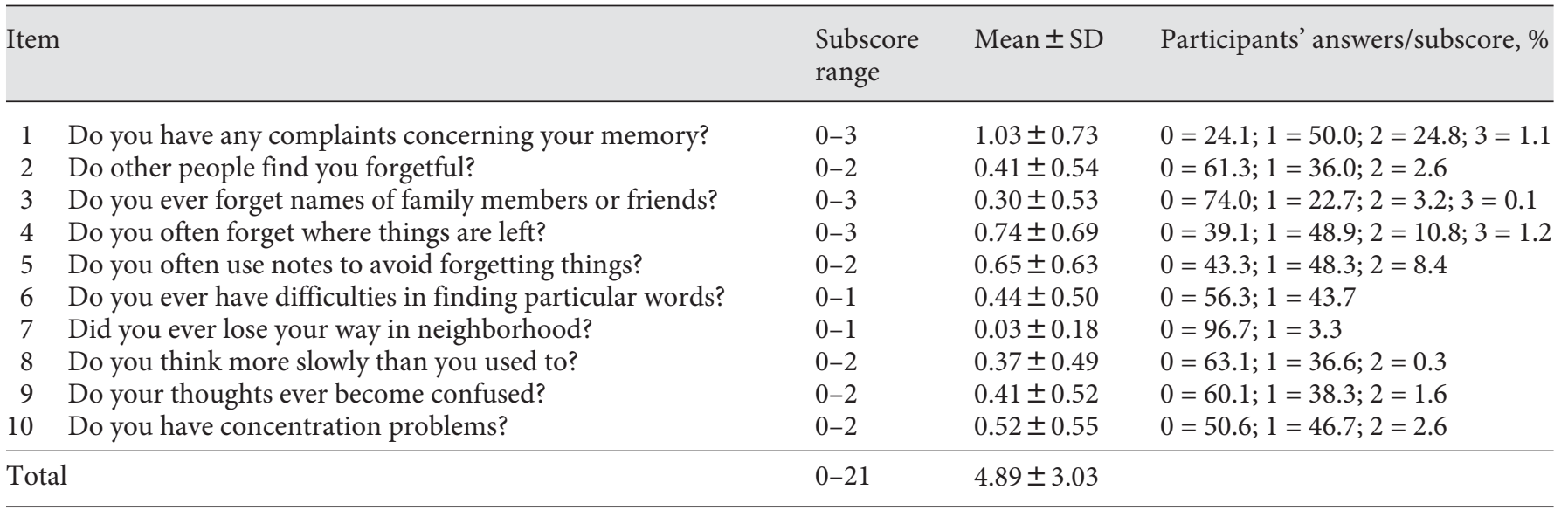

Scoring of items 1, 3 and 4: $0=$ no; $1=$ yes, but no problem; $2=$ yes, problem; 3 =yes, serious problem.

Scoring of items 2 and 5: $0=$ no; 1 = yes, sometimes; 2 = yes, often.

Scoring of items 6 and 7: $0=$ no; $1=$ yes.

Scoring of items $8-10: 0=$ no; 1 = yes; 2 = yes, serious problem.

their complaints to potentially reversible and more manageable memory-extrinsic causes like stressful life events and concentration problems, while the elderly could attribute their complaints to a group of less reversible and less manageable memory-intrinsic causes like ageing [7, 27]. We thus analyzed in more detail whether there were differences in individual items of the SMC scale associated with age. We found that younger people reported

Memory Complaints in Young and

Elderly Healthy People that they were more frequently told by others that they were forgetful (item 2) and would more often take notes (item 5). Older people were more likely to report becoming transiently confused (item 9). It is noteworthy that no age-related differences were found in the majority of memory complaints reflected in the SMC scale.

It is interesting that younger individuals more frequently reported that they were told by others that they 
were forgetful. It could be that people may have a lower tolerance to subtle memory difficulties in young subjects, and would tend to remark minor memory difficulties in their younger as compared to older relatives and friends. People generally believe that some degree of memory impairment is to be expected as they get older [28]. The effects of social interest on responses to memory items [29] and also the reluctance to acknowledge the existence of a condition that might be negatively associated with being old or senile [28] must also be taken into account. It is worth considering that people might abstain from remarking memory difficulties in older relatives and friends because these may be felt as damaging to the elderly person.

Another interesting finding about younger participants is that they reported that they would more often take notes. Young subjects probably had more tasks and professional responsibilities that would require a higher level of memory performance, although there is some evidence that, under specific experimental conditions, older people might display a better prospective memory [30]. Certainly, as people grow older, they attempt to compensate for memory deficits by making greater use of physical reminders and forward planning, and adults who have many obligations may develop an organizational system that minimizes prospective memory failures [31].

Although participants seldom reported they were transiently confused, this report was more frequent in elderly people. It is interesting that patients in the initial phases of Alzheimer's disease may report transient bewilderment [32]. It cannot be excluded that some of the elderly participants in the present study, in spite of having a normal MMSE, could suffer from an incipient dementia worse than younger adults in tasks that entail attentional processes [33]. On the other hand, adults with attention deficit hyperactivity disorder showed significant impairment in memory performance compared with normal centration problems (item 10) were found between youngthe development of cognitive decline in the elderly is still controversial [6]. It would be interesting to test whether any SMC item, or combination of items, could discrimiinitial phases of Alzheimer's disease, namely mild cognithe SMC items may not be useful for this purpose, inas-

much as they are more altered in younger subjects than in older subjects.

Although for this study we recruited a very large sample of individuals in a community setting, and applied a detailed scale on memory complaints, several limitations must be pointed out. Participants were volunteers who agreed to do a general health survey where an evaluation of memory complaints was contained, and might not be entirely representative of the community. However, it should be emphasized that we did not recruit individuals with memory complaints seeking clinical assistance. An objective memory assessment was not performed, and thus it is not possible to compare objective memory performance with subjective memory complaints. Previous studies reported the influence of personality characteristics [35] and anxiety symptoms [36] on the emergence of memory complaints. In the present study, anxiety symptoms and personality traits were not evaluated, and this should be considered in future research.

In conclusion, memory complaints are frequent in both young and elderly subjects, but the use of a detailed assessment reveals age-related differences in the type of complaints.

\section{Acknowledgements}

Supported by Calouste Gulbenkian Foundation and Fundação para a Ciência e Tecnologia. The authors thank Memoclínica and Santa Casa da Misericórdia de Lisboa for the facilities provided and Dr. Teresa Botelho for reviewing the manuscript. disorder.

Several studies have shown that older adults perform controls [34]. However, no differences in reporting coner and older participants in the present study.

The relationship between subjective complaints and nate between healthy elderly subjects and those in the tive impairment. The present results suggest that some of

References
Gerontology 2010;56:272-277
1 Gagnon M, Dartigues JF, Mazaoux JM, et al: Self-reported memory complaints and memory performance in elderly French community residents: results of the PAQUID research program. Neuroepidemiology 1994; 13:145-154.

2 Jonker C, Geerlings MI, Schmand B: Are memory complaints predictive for dementia? A review of clinical and populationbased studies. Int J Geriatr Psychiatry 2000; 15:983-991.

- 3 Jungwirth S, Fischer P, Weissgram S, Kirchmeyr W, Bauer P, Tragl KH: Subjective memory complaints and objective memory impairment in the Vienna-Transdanube Aging Community. J Am Geriatr Soc 2004;52:263268.

4 Ercoli L, Siddarth P, Huang SC, et al: Perceived loss of memory ability and cerebral metabolic decline in persons with the apolipoprotein E-IV genetic risk for Alzheimer disease. Arch Gen Psychiatry 2006;63:442448.
Ginó/Mendes/Maroco/Ribeiro/ Schmand/de Mendonça/Guerreiro 
5 Reid LM, MacLullich AMJ: Subjective memory complaints and cognitive impairment in older people. Dement Geriatr Cogn Disord 2006;22:471-485.

6 Mitchell AJ: The clinical significance of subjective memory complaints in the diagnosis of mild cognitive impairment and dementia: a meta-analysis. Int J Geriatr Psychiatry 2008;23:1191-1202.

7 Ponds RWHM, Commisaris KJAM, Jolles J: Prevalence and covariates of subjective forgetfulness in a normal population in The Netherlands. Int J Aging Hum Dev 1997;45: 207-221.

8 Basset SS, Folstein MF: Memory complaint, memory performance and psychiatric diagnosis: a community study. J Geriatr Psychiatry Neurol 1993;6:105-111.

$\checkmark 9$ Abdulrab K, Heun R: Subjective memory impairment. A review of its definitions indicates the need for a comprehensive set of standardised and validated criteria. Eur Psychiatry $2008 ; 23: 321-330$.

-10 Schmand B, Jonker C, Hooijer C, Lindeboom J: Subjective memory and memory complaints may announce dementia. Neurology 1996;46:121-125.

-11 Mendes T, Ginó S, Ribeiro F, Guerreiro M, de Sousa G, Ritchie K, de Mendonça A: Memory complaints in healthy young and elderly adults: reliability of memory reporting. Aging Ment Health 2008;12:177-182.

$\checkmark 12$ Folstein MF, Folstein S, McHugh PR: MiniMental State: a practical method for grading the cognitive state of patients for the clinician. J Psychiatr Res 1975;12:189-198.

13 Guerreiro M, Silva AP, Botelho MA, Leitão O, Castro-Caldas A, Garcia C: Adaptation to the Portuguese population of the Mini-Mental State Examination (in Portuguese). Rev Port Neurol 1994;1:9-10.

14 Uhlmann RF, Larson EB: Effect of education on the Mini-Mental State Examination as a screening test for dementia. J Am Geriatr Soc 1991;39:876-880.
15 Ginó S, Guerreiro M, Garcia C: Subjective Memory Complaints; in Tests and Scales in Dementia, ed 2. Lisbon, Group for the Study of Brain Aging and Dementia, 2007.

16 Yesavage JA, Brink TL, Rose TL, et al: Development and validation of a geriatric depression screening scale: a preliminary report. J Psychiatr Res 1983;17:37-49.

17 Barreto J, Leuschner A, Santos F, Sobral M: Geriatric Depression Scale; in Tests and Scales in Dementia, ed 2. Lisbon, Group for the Study of Brain Aging and Dementia, 2007.

18 Morris JC, Heyman A, Mohs RC, et al: The consortium to Establish a Registry for Alzheimer's Disease (CERAD). I. Clinical and neuropsychological assessment of Alzheimer's disease. Neurology 1989;39:11591165.

19 Beck A, Ward C, Mendelson M, Mock J, Erbaugh J: An inventory for measuring depression. Arch Gen Psychiatry 1961;4:561-571.

20 Serra AV, Abreu JP: Validation of the clinical depressive syndromes. I. Use of the Beck Depressive Inventory in a Portuguese sample of depressive patients (in Portuguese). Coimbra Med 1973;20:623-644.

21 Meara J, Mitchelmore E, Hobson P: Use of the GDS-15 geriatric depression scale as a screening instrument for depressive symptomatology in patients with Parkinson's disease and their carers in the community. Age Ageing 1999;28:35-38.

22 Mack JL, Patterson MB: CERAD Behavior Rating Scale for Dementia. Durham, Consortium to Establish a Registry for Alzheimer's Disease, 1991.

23 McSweeney M, Porter AC: Small sample properties of nonparametric index of response and rank analysis of covariance. Occasional paper No. 16, Office of Research Consultation. East Lansing, Michigan State University, 1971.

24 Katz BM, McSweeney M: A multivariate Kruskal-Wallis test with post-hoc procedures. Mult Behav Res 1980;15:281-297.
25 Quade O: Rank analysis of covariance. J Am Stat Assoc 1967;62:1187-1200.

-26 McCrae RR, Costa PT Jr, Pedroso de Lima M, et al: Age differences in personality across adult life span: parallels in five cultures. Dev Psychol 1999;35:466-477.

27 Derouesné C, Lacomblez L: La plainte mnésique: épidémiologie et démarche diagnostique. Presse Med 2000;29:858-862.

28 Cutler SJ, Grams AE: Correlates of self-reported everyday memory problems. J Gerontol 1988;43:582-590.

29 Mol MEM, Ruiter RAC, Verhey FRJ, Dijkstra J, Jolles J: A study into the psychosocial determinants of perceived forgetfulness: implications for future interventions. Aging Ment Health 2008;12:167-176.

30 Rendell PG, Thomson DM: Aging and prospective memory: differences between naturalistic and laboratory tasks. J Gerontol B Psychol Sci Soc Sci 1999;54:256-269.

- 31 Loewen ER, Shaw RJ, Craik FIM: Age differences in components of metamemory. Exp Aging Res 1990;16:43-48.

32 DeBaggio T: Losing My Mind - An Intimate Look at Life with Alzheimer's. Clearwater, Touchstone Books, 2003.

33 Bisiacchi PS, Borella E, Bergamaschi S, et al: Interplay between memory and executive functions in normal and pathological aging. J Clin Exp Neuropsychol 2008;30:723-733.

34 Seidman LJ, Biederman J, Weber W, et al: Neuropsychological function in adults with attention-deficit hyperactivity disorder. Biol Psychiatry 1998;44:260-268.

- 35 Comijs HC, Deeg DJH, Dik MG, Twisk JWR, Jonker C: Memory complaints: the association with psycho-affective and health problems and the role of personality characteristics. A 6-year follow-up study. J Affect Disord 2002;72:152-165.

-36 Kizilbash AH, Vanderploeg RD, Curtiss G: The effects of depression and anxiety on memory performance. Arch Clin Neuropsychol 2002;17:57-67. 